\title{
Autologous Ovarian Tissue Transplantation
}

National Cancer Institute

\section{Source}

National Cancer Institute. Autologous Ovarian Tissue Transplantation. NCI Thesaurus.

Code C116463.

Ovarian transplantation using autologous tissue. The goal of this procedure is to restore both endocrine function and reproductive function. 